\title{
MUDANÇA, LÓGICAS INSTITUCIONAIS E EMERGÊNCIA DE NOVOS ATORES: A RENATURALIZAÇÃODA MATERNIDADE NO BRASIL
}

\author{
Changes, institutional logics and emergence of new actors: \\ the renaturation of maternity in Brazil
}

\author{
Sara Fernandes Picheth* \\ João Marcelo Crubellate**
}

\section{RESUMO}

A liderança mundial do Brasil quanto à proporção de nascimentos realizados por cesariana desencadeou iniciativas governamentais e respostas de grupos de mulheres que trabalham para reverter essa situação, evidenciando iniciativas para a renaturalização da maternidade. Destacam-se, nesse contexto, atores-chave para promulgação das novas práticas quanto ao parto e criação dos filhos. Com base nisso, objetivamos, nesse artigo, investigar a emergência de novos atores envolvidos no campo da maternidade, durante processos de mudança em lógicas institucionais, denominadas aqui de lógica intervencionista e lógica natural de maternidade. A partir de um levantamento documental na área da saúde e de um estudo de caso em um grupo de apoio às gestantes e mães da cidade de Maringá (PR), evidenciou-se que inconsistências percebidas entre lógicas contraditórias deram oportunidade para a emergência de novos atores que atuaram como legitimadores das mudanças, fornecendo sustentação para outras lógicas e possibilitando a sua expansão recursiva no campo.

Palavras-chave: Lógica Institucional. Mudança Institucional. Emergência de Novos Atores. Maternidade.

\begin{abstract}
The worldwide leadership of Brazil regarding the proportion of births carried out by cesarean section has triggered governmental initiatives and responses by women's groups working to reverse this situation, evidencing initiatives for the renaturation of maternity. In this context, key actors for the promulgation of new practices regarding childbirth and child rearing are highlighted. Based on this, we aim to investigate the emergence of new actors involved in the field of maternity, during processes of change in institutional logics, herein named interventionist logic and natural logic of motherhood. Based on a documentary research in the field of health and a case study in a support group for pregnant women and mothers in the city of Maringa (PR), it was demonstrated that perceived inconsistencies between contradictory logics provided opportunity for the emergence of new actors who acted as legitimators of the changes, providing support for other logics and enabling their recursive expansion in the field.
\end{abstract}

Keywords: Institutional logics. Institutional change. Emergence of new actors. Maternity.

\footnotetext{
* Mestre em Administração pela Universidade Estadual de Maringá. Doutoranda em Administração pela Universidade Estadual de Maringá (UEM) - Maringá (PR), Brasil. E-mail: sarafpicheth@gmail.com. ORCID: 0000-0002-4081-731X

** Doutor em Administração pela Fundação Getúlio Vargas (FGV-SP). Professor no Departamento de Administração e no Programa de Pós-graduação em Administração da Universidade Estadual de Maringá (UEM) - Maringá (PR), Brasil. E-mail: jmcrubellate@uem.br. ORCID: 0000-0003-1446-8248
} 


\section{INTRODUÇÃO}

S erá que a maternidade segue uma lógica institucional? Ou os cuidados com a reprodução dos seres humanos são apenas mais uma função biológica? Podem práticas promulgadas quanto à gravidez, parto e criação dos filhos estarem carregadas de significados culturais, ritos de afeto, técnicas científicas, sujeitos a mudanças ao longo da história? Neste artigo, defendemos que sim.

Por muito tempo, a maternidade foi concebida como uma função intrínseca da mulher. Por sua capacidade única de gerar e nutrir seu filho (MOURA; ARAÚJO, 2004), era restrita a um olhar biológico. No entanto, ao expandi-la enquanto instituição, isto é, regime prático constituído de significados (FRIEDLAND, 2009), Davis (2012) e Ross (1993) a caracterizam-na como um estado tanto cultural quanto biológico. Segundo as autoras, a maternidade é uma área em que uma variedade de discursos e práticas de diferentes áreas se encontram - educação, mercado de trabalho, estado, saúde, psicologia, religião - envolvendo não apenas a mãe, mas diversos atores em suas práticas. Em função disso, em graus variados, a maternidade lida com o que Greenwood e colegas (2011) chamam de complexidade institucional, a exposição a prescrições incompatíveis de múltiplas lógicas. Tal exposição gera desafios e tensões que os atores devem responder, levando a uma heterogeneidade de práticas e à mudança institucional (GREENWOOD et al., 2011; OCASIO; RADOYNSVK, 2016)

No Brasil esta complexidade vem se destacando a partir das recorrentes mudanças, tanto em relação ao sistema obstétrico (tipo e local de parto), quanto em relação às práticas e modos de criação dos filhos, evidenciando que mais de uma lógica de maternidade coexiste no campo. Apesar de o país ser caracterizado por um modelo predominante tecnocrático e intervencionista (RATTNER, 2009), com alta incidência de cesárea (VALADARES, 2017) e baixo índice de amamentação (SUSIN; GIUGLIANI; KUMMER, 2005), nos últimos anos, diversas iniciativas legais (ANS, 2015) e sociais (DINIZ, 2005; BRASIL, 2001) têm se sobressaído, defendendo-se a retomada da naturalização do parto e do nascimento. $A$ liderança mundial do Brasil quanto à proporção de nascimentos realizados por cesariana - considerado um problema de saúde pública - desencadeou iniciativas governamentais, bem como respostas de grupos de mulheres que trabalham para reverter essa situação, originando processos de mudança de uma lógica intervencionista para uma mais natural, facilitados por alguns atores-chave.

A instituição da maternidade, deste modo, configura-se como um domínio de contestação no qual, negociações e lutas entre diversos atores - mães, família, estado, médicos, enfermeiras e doulas -, constantemente ocorrem em face de suas respectivas lógicas (WREDE, 2001). Tal evidência ratifica o papel central dos atores na mudança de lógicas institucionais (ANSARI; WIJEN; GRAY, 2013; LOUNSBURY; BOXENBAUM, 2013; ALMANDOZ, 2014), em especial a emergência de novos atores (GREENWOOD; SUDDABY; HININGS, 2002) que aparecem como fator chave para institucionalização das novas lógicas de maternidade.

Neste sentido, este artigo pretende contribuir com a discussão desses temas a partir da perspectiva da lógica institucional. Lógicas institucionais abrangem crenças, valo- 
res, regras e padrões históricos que foram socialmente construídos e que atribuem sentido à realidade social (THORNTON; OCASIO, 1999). O conceito descreve as práticas e crenças contraditórias inerentes às instituições das sociedades ocidentais modernas (THORNTON; OCASIO, 2008). Estas são concebidas como sistemas interinstitucionais constituídos por múltiplas ordens entrelaçadas e marcadas por interdependência e contradições. Ao explorarem essas contradições, indivíduos e organizações transformam as relações institucionais da sociedade (FRIEDLAND; ALFORD, 1991; THORNTON; OCASIO, 2008). E, dado que o foco em lógicas concorrentes direciona a atenção para o caráter heterogêneo da atuação das lógicas institucionais sobre organizações e indivíduos (GREENWOOD; HININGS; WHETTEN, 2014; LOUNSBURY, 2007), considera-se apropriada esta perspectiva como lente teórica (MICELOTTA; LOUNSBURY; GREENWOOD, 2017).

A análise das lógicas institucionais demanda atenção aos atores e contextos nos quais as práticas, direcionadas pelas lógicas, ocorrem (LOUNSBURY; BOXENBAUM, 2013) e como eles afetam os processos de mudança. Uma vez que lógicas institucionais representam modos de referências que influenciam as escolhas dos atores, a construção de sentido vinculado a estas e o vocabulário utilizado para motivar a ação desempenhada (THORNTON; OCASIO; LOUNSBURY, 2012), a noção de atores é fundamental para a discussão da temática, já que eles são vistos como transportadores de influências institucionais para 0 grupo (ALMANDOZ, 2014).

Apesar de reconhecida essa importância (ANSARI; WIJEN; GRAY, 2013; MCPHERSON; SAUDER, 2013) e da emergência de atores ser apontada como um dos estágios de mudança institucional (GREENWOOD; SUDDABY; HININGS, 2002), a relação entre estes aspectos ainda permanece pouco explorada. Esta pesquisa representa, portanto, contribuição ao estudo da teoria institucional, da saúde pública e das ações estratégicas dos grupos sociais com foco na defesa de direitos das mulheres. Tratamos aqui das mudanças em lógicas institucionais de maternidade, denominadas de lógica intervencionista e lógica natural, a partir do contexto social, estatal, mercadológico e profissional (FRIEDLAND; ALFORD, 1991; REAY; HININGS, 2009; GOODRICK; REAY, 2011; RAMUS; VACCARO; BRUSONI, 2017) em que estão inseridas e da atuação de atores envolvidos nesses processos. Evidenciamos que processos de desinstitucionalização e reinstitucionalização (GREENWOOD; SUDDABY; HININGS, 2002) possibilitam a emergência de novos atores no campo, que por sua vez contribuem para a legitimação das novas lógicas, reforçando a sua influência expandida recursivamente no campo.

Orientamos nossas reflexões a partir de três questões que supomos avançar e contribuir com as pesquisas em lógica e mudança institucional. Primeiramente, indagamos: como elementos contextuais influenciaram os processos de mudança em lógicas institucionais de maternidade? A partir da literatura, identificamos como principais aspectos contextuais relacionados às lógicas de maternidade: a estrutura familiar, o movimento de humanização do parto e nascimento, a criação de grupos de mulheres e índices de mortalidade/morbidade materna e neonatal, num âmbito social; os incentivos e regulamentações governamentais como contexto estatal; no âmbito mercadológico, o mercado de trabalho e o desenvolvimento da indústria alimentícia, farmacêutica e de aparatos médicos; e o avanço da ciência obstétrica e de técnicas de suporte a ela como contexto profissional. 
Em sequência, questionamos: como a emergência de novos atores decorreu dos processos de mudança nas lógicas institucionais de maternidade? Identificamos como alguns dos principais atores emergentes no campo os profissionais da saúde, grupos de apoio, movimento de mulheres e creche parental. Finalmente, propomos: como a emergência desses atores, a partir de mudanças em lógicas institucionais, legitimou a institucionalização da retomada da lógica natural de maternidade?

Para responder essas questões, conduzimos um estudo para rastrear a evolução do campo da maternidade no Brasil, analisando as últimas cinco décadas, e realizamos um estudo de caso no Maternati - Grupo de Apoio a Gestantes e Mães de Maringá/PR - o qual divulga uma maternidade natural (em especial o parto natural), incentivando e apoiando mulheres e casais que optam por esse tipo de maternidade, em suas várias etapas. Nosso estudo ilustra como se dá a relação recursiva entre organizações, seus participantes e o contexto institucional, na medida em que as mudanças em lógicas institucionais ocorrem em oposição e sobreposição às demais lógicas de maternidade.

\section{MATERNIDADE ENQUANTO INSTITUIÇÃO}

Por um longo período a maternidade foi pensada como sendo função feminina por excelência. Atrelada aos interesses econômicos do Estado, propagava-se o discurso de que era natural que os cuidados da criança fossem responsabilidade da mulher, uma vez que só ela era capaz de gestar, parir e amamentar (MOURA; ARAÚJO, 2004). Contudo, de acordo com Ross (1993), a maternidade constitui-se de práticas culturais e sociais interligadas com uma história sujeita a mudança. Desse modo, baseados em Friedland et al (2014), propomos neste estudo adotar a noção de maternidade como uma instituição infundida de sua própria lógica, composta de um conjunto de práticas materiais (os vários tipos de atividades realizadas em suporte às mães e gestantes e aquelas que elas próprias desempenham em suas maternidades) e de construções simbólicas (categorias significativas de valor e dimensões de diferença).

Assim, analisando historicamente, não é possível considerar apenas uma lógica institucional no campo da maternidade. Práticas, discursos e símbolos foram sendo modificados ao longo do tempo, provocando divergências mesmo entre pessoas da mesma geração, de modo que as relações institucionais foram sendo transformadas à medida que os indivíduos e as organizações exploravam a multiplicidade e as contradições evidentes, circunstância similar àquela descrita, genericamente, por Friedland e Alford (1991). Tal complexidade possibilitou momentos em que os atores sociais relevantes reproduziram padrões já aceitos, e que impulsionaram mudanças em práticas, o que levou a transformações nas lógicas institucionais (THORNTON; OCASIO; LOUNSBURY, 2012).

Até à década de 1970 a maternidade se caracterizava pela dominância de uma lógica natural, compreendendo saberes tradicionais e empíricos concernentes ao parto e ao nascimento, transmitidos entre as mulheres de geração em geração. Compreendia também o nascimento como evento íntimo e feminino, ocorrendo predominantemente em domicílio, com assistência de parteiras e outras mulheres (parentes/vizinhas) mais experientes, formando uma rede de apoio. Predominava o aleitamento materno. Nessa lógica, a maternidade 
se caracterizava como função das mulheres, que se dedicavam integralmente à casa e aos filhos (BRENES, 1991; BRASIL, 2001; DIAS, 2007).

Entre o final dos anos 1960 e 1980, no entanto, essa estrutura familiar, caracterizada pelo homem como provedor do lar e pela mulher como cuidadora da casa e de seus membros, começou a mudar. 0 crescente ativismo feminista, dentre outros aspectos, encorajou ainda mais uma reavaliação do lugar das mulheres na família e na sociedade (DAVIS, 2012). Em meio ao processo de industrialização do país, a renda feminina se tornou parte fundamental da renda familiar o que, aliado à influência de movimentos feministas e à introdução de pílulas contraceptivas, resultou em quedas das taxas de fecundidade e consequente diminuição no tamanho das famílias (FAVARO, 2014; DAVIS, 2012). Ou seja, um novo cenário caracterizado por aumento da escolarização feminina, entrada e permanência no mercado de trabalho e diminuição do tamanho das famílias, passou a predominar. Segundo Leone, Maia e Baltar (2010), o número médio de filhos por mulher, que era de 5,8 em 1960, reduziu-se para 2,3 filhos no ano 2000.

As primeiras mudanças desse cenário acompanharam também iniciativas em busca da redução da mortalidade materna e neonatal e várias conquistas científicas na área da saúde, as quais inauguraram a pesquisa detalhada do corpo feminino, com a produção de saber anatômico e fisiológico da mulher, produzindo um cenário favorável à entrada do saber médico na obscuridade mágica do nascimento humano. A tecnologia substituía, então, o lugar ocupado pela intuição e pela experiência (BRENES, 1991; JONES, 2007). Assim, avanços científicos e desenvolvimento da indústria alimentícia foram fundamentais para a mudança de predomínio da lógica natural para uma lógica intervencionista. Se em 1970 o índice de cesáreas realizadas em hospitais públicos brasileiros era de aproximadamente 14,6\%, em 1980 ele saltou para 31\% (FAÚNDES; CECATTI, 1991). Essa tendência perdura até o presente, como atestam os números atuais no Brasil. Em 2009 esse índice alcançou $50,1 \%$ do total de partos (tornando o Brasil o primeiro país a ter mais da metade dos bebês nascendo por via cirúrgica), e em 2016, já era de 55,5 \% dos nascimentos (VALADARES, 2017).

A popularização das cesáreas no Brasil ocorreu na década de 1970, principalmente em razão de as mulheres aproveitarem a mesma cirurgia para realizar a laqueadura tubária, método contraceptivo permanente (VELHO et al., 2012). Essas e outras transformações que ocorriam relacionadas ao parto, anteriormente citadas, começavam a firmá-lo como um evento médico. 0 parto passava a ser vivenciado de forma pública, dentro de hospitais e maternidades e cercado da presença de outros atores, sendo a assistência realizada por uma equipe especializada (médico obstetra, anestesista, enfermeira, auxiliar de enfermagem e pediatra) cada um com sua respectiva função, dentro do novo cenário do parto (BRASIL, 2001; DIAS, 2007).

Complementarmente, como todo o cenário de evolução tecnológica e científica e transformações sociais, identificado no âmbito da questão do parto, essas mudanças também refletiram na maternidade em geral. Moura e Araújo (2004) salientam que durante um longo período a maternidade era pensada como função feminina por excelência, relacionada à natureza da mulher, que exercia não apenas a função de mãe, mas também de nutrícia, educadora e professora. Contudo, as transformações que foram ocorrendo na sociedade contemporânea levaram à constituição de uma nova maternidade. Embora ainda 
valorizada e investida, a gravidez já não ocupava um lugar central na vida das mulheres. O papel feminino deveria conter a maternidade, mas não deveria ser resumido a ela, o que representaria um retrocesso. Era igualmente fundamental o desempenho de outros papéis além do ser mãe (MOURA; ARAÚJO, 2004; LO BIANCO, 1985).

Surgem assim dilemas em relação à vida materna versus a vida profissional. Reportagens publicadas na Revista Veja, de 1991 a 2003, bem como abordadas academicamente por Carvalho Neto, Tanure e Andrade (2010); Turner e Norwood (2013), e Carvalho (2016), relatam o impasse de muitas mulheres que decidem adiar a maternidade para construir uma carreira profissional, mas depois têm dificuldade para engravidar devido ao avanço da idade. $\mathrm{E}$, quando conseguem, surge o dilema de conciliar a maternidade com a profissão. A mulher acaba recorrendo a outros meios para criação dos filhos, como a escolarização precoce das crianças e a terceirização para babás ou, ainda, restringindo a prática da amamentação em detrimento da profissão.

Similarmente, a atuação do marido também sofreu transformações; sua presença em todos os momentos da gestação é valorizada (MOURA; ARAÚJO, 2004). A escolha pela maternidade/paternidade deixa de ser autoevidente e se torna sujeita a discussão pelo casal. Além disso, o envolvimento de outros atores ganha importância. O lugar que anteriormente era ocupado exclusivamente pela família, passa a envolver médicos obstetras, pediatras, anestesistas e outros técnicos, reforçando-se uma relação de maior dependência dos pais para com os especialistas (SALEM, 1985). A maternidade, assim, vai se configurando como um conjunto de relacionamentos e variadas práticas específicas interligadas com uma história e sujeita a mudanças (ROSS, 1993).

\section{LÓGICAS INSTITUCIONAIS, MUDANÇA E A EMERGÊNCIA DE NOVOS ATORES}

\section{LÓGICAS INSTITUCIONAIS E CONTEXTO SOCIAL}

Friedland e Alford (1991) foram os primeiros a sistematicamente tratarem da noção de lógica institucional. Para eles, lógicas (conjuntos de práticas materiais e construções simbólicas) são princípios organizativos elaborados por organizações e indivíduos. Mais recentemente Friedland et al (2014) ampliaram esse conceito, definindo lógicas institucionais como ordens de produção que unem objetos, sujeitos e práticas em conjuntos cuja referencialidade é interna. Ou seja, ordens nas quais uma substância institucional é continuamente promulgada pelas próprias práticas institucionalmente orientadas.

Os objetos institucionais são apontados por meio de nomes e desempenhados através da prática; são construídos em torno de substâncias - razões - não observáveis, nas quais práticas particulares são entendidas como sua promulgação ou produção. Prática, por sua vez, não é vista apenas como um sinal; ela funciona como simbolização ou desempenho, sendo dependente das substâncias. E o sujeito, sua formação investida em e por um valor particular, também constitui elemento essencial à operação de qualquer lógica institucional que conclui o conjunto, ou conforme denominado pelos autores, a troika (FRIEDLAND, 2011; FRIEDLAND et al., 2014). 
Um dos aspectos de destaque no campo tem sido a concepção da multiplicidade de lógicas institucionais simultaneamente interdependentes e contraditórias. Nesses casos, as respostas às lógicas variam à medida que as contradições são exploradas e os sistemas de significados embutidos fornecem expectativas inconsistentes (FRIEDLAND; ALFORD, 1991; THORNTON; OCASIO; LOUNSBURY, 2012). Consequentemente, o foco da literatura em lógica institucional expandiu seu escopo para a complexidade de lógicas plurais, as quais possibilitam e direcionam para a divergência e multiplicidade de respostas às pressões ambientais (LEE; LOUNSBURY, 2015; GREENWOOD et al., 2011; BERTELS; LAWRENCE, 2016), e para a influência das lógicas no comportamento individual e grupal dentro e entre organizações (LOUNSBURY; BOXEBAUM, 2013).

Estudos como os de Dunn e Jones (2010), Thornton e Ocasio (1999) e Greenwood et al (2014) mostram como a relação entre respostas organizacionais e complexidade institucional é moldada, seja direta ou indiretamente, pelas lógicas institucionais que os atores promulgam, de modo que tais lógicas atuam como filtro que permite que os atores interpretem e respondam às pressões cotidianas (ver também LEE; LOUNSBURY, 2015).

À vista disso, as lógicas institucionais têm sido cada vez mais utilizadas para ilustrar a contingência histórica das instituições e a dinâmica de campos organizacionais (QUATTRONE, 2015). De acordo com Lee e Lounsbury (2015, p. 847), "[...] os valores e crenças associados às lógicas institucionais não estão flutuando livremente, mas estão concretamente representados nas práticas e comportamentos padronizados dos atores que agem como portadores de lógicas em contextos específicos". Por conseguinte, a análise da lógica institucional deve estar inserida no respectivo contexto social que se encontra para que seja mais bem explicada (THORNTON; OCASIO, 2008; FRIEDLAND; ALFORD, 1991; LOUNSBURY, 2007).

Eventos históricos são fundamentais para compreender as manifestações particulares de lógica que ocorrem em um ponto do tempo (LOUNSBURY, 2007). Eles não apenas explicam as condições para ação imediata, como também apontam características sociais que representam as respostas promulgadas $(\mathrm{MUTCH}, 2018)$. Por conseguinte, estudos nesta abordagem pressupõem um núcleo central que afirma que para entender o comportamento individual e organizacional deve-se localizar a lógica em um contexto social e institucional. Tal contexto poderá tanto regularizar o comportamento quanto oferecer oportunidade para agência e mudança (THORNTON; OCASIO, 2008; FRIEDLAND; ALFORD, 1991), uma vez que ele restringe a capacidade dos atores de conceber alternativas aos arranjos institucionais existentes (NIGAM; OCASIO, 2010).

Assim, o impacto de diferentes elementos contextuais pode organizar diferentemente práticas e profissões (GOODRICK; REAY, 2011) ou, no caso, a própria maternidade. Logo, no presente estudo, tomamos como foco aspectos contextuais centrais: elementos estatais (controle e influência do estado), mercadológicos (configuração do mercado de trabalho, competição livre e desregulada, busca por eficiência, baixos custos, preferências de consumidores e desenvolvimento de indústria), sociais (índices demográficos, estrutura familiar) e profissionais (influência de conhecimentos específicos respectivos a uma profissão especializada) (FRIEDLAND; ALFORD, 1991; GOODRICK; REAY, 2011; REAY; HININGS, 2009). 


\section{MUDANÇAS EM LÓGICAS INSTITUCIONAIS}

Competição entre lógicas institucionais alternativas tem orientado pesquisas em mudança institucional, posto que lógicas institucionais governando a prática não são permanentes, mas podem mudar à medida que algumas audiências são observadas mais consistentemente do que outras (SMETS; MORRIS; GREENWOOD, 2012). Alguns estudos tratam de mudanças em lógicas como efeitos de substituição de um período relativamente estável de crenças e atividades por outro, isto é, quando modos de referência nas escoIhas dos atores são substituídos por outros (COSTA; MELLO, 2017; THORNTON; OCASIO, 2008). Nesses casos, a mudança ocorre quando uma lógica dominante impulsionando as práticas de nível de campo é abandonada e outra toma o seu lugar (DUNN; JONES, 2010; LOUNSBURY, 2007).

Estudos mais recentes, por outro lado, evidenciaram que mudanças em lógicas não implicam necessariamente uma ruptura radical por competição de modelos. Elas também podem ser menos lineares e ocorrerem por processos de acumulação, em que dimensões teorizadas individualmente se acumulam ao longo do tempo (NIGAM; OCASIO, 2010; OREG et al., 2018), possibilitando a coexistência de múltiplas lógicas (REAY; HININGS, 2009; NICOLINI et al., 2016; GREVE; ZHANG, 2017; JANCSARY et al., 2017). Tais evidências podem se manifestar a partir da fusão de diferentes pontos de vista, por combinação (BINDER, 2007) e hibridização (BATTILANA; DORADO, 2010), de emergência de nova lógica (NIGAM; OCASIO, 2010) ou ainda por cada ordem promovendo seus próprios valores e práticas (GREVE; ZHANG, 2017), demonstrando também esforços de complementaridade entre lógicas plurais (GOODRICK; REAY, 2011).

Admitindo-se que lógicas institucionais são formadas por uma troika, mudanças nas lógicas, assim, operam por meio de variação nos elementos que as compõem. A análise das relações entre os elementos decompostos possibilita compreender os processos e tipos de mudança ocorridos (FRIEDLAND et al., 2014; THORNTON; OCASIO; LOUNSBURY, 2012). Logo, não apenas alterações na substância da lógica implicam mudanças na prática, como mudanças práticas também podem proporcionar condições que levam a mudanças na substância, gerando contradições internas na própria lógica (FRIEDLAND, 2009). A alteração em práticas existentes ou a criação de novas desempenham papel central na criação e transformação de lógicas institucionais (NIGAM; OCASIO, 2010; THORNTON; OCASIO; LOUNSBURY, 2012), devendo, portanto, serem consideradas em dualidade (COSTA; MELLO, 2017; FRIEDLAND et al., 2014; MUTCH, 2018).

Para compreender mudança institucional, estudos relacionam fortemente os processos de atenção a eventos (GREENWOOD; SUDDABY; HININGS, 2002; NIGAM; OCASIO, 2010; OREG et al., 2018); teorização (THORNTON; OCASIO; LOUNSBURY, 2012; LOK, 2010; OCASIO; LOEWENSTEIN; NIGAM, 2015) e representação (NIGAM; OCASIO, 2010) como estágios necessários para a emergência e mudança de lógicas institucionais.

Mudanças institucionais podem ter início a partir de eventos ou choques que desestabilizam as práticas estabelecidas, podendo levar a sua desinstitucionalização (GREENWOOD; SUDDABY; HININGS, 2002) e ao desdobramento de episódios de mudança (OREG et al., 2018). A atenção a eventos - atividades e processos sobrepostos que ocorrem ao longo do tempo -, moldam a percepção dos atores não apenas do evento em si, mas 
também de aspectos contextuais mais amplos do respectivo campo. Essa atenção seletiva torna salientes aspectos do ambiente que podem desencadear, com o tempo, a teorização de novas lógicas institucionais (NIGAM; OCASIO, 2010).

A teorização de uma lógica envolve a elaboração de modelos abstratos que definem papéis e relações entre atores e estruturas nas quais eles operam (NIGAM; OCASIO, 2010), elucidam propriedades de novas práticas (GREENWOOD; SUDDABY; HININGS, 2002) e criam construções simbólicas LOK, 2010). É um processo fundamental, portanto, para expor contrariedades e tornar modelos existentes menos atrativos, e conferir legitimidade à nova prática, já que traduz as ideias em formatos compreensíveis e entendíveis (GREENWOOD; SUDDABY; HININGS, 2002; THORNTON; OCASIO; LOUNSBURY, 2012; LOK, 2010).

A teorização também se fortalece a partir da representação de novas formas do ambiente, em que os atores se amparam em formas e aspectos específicos de um campo como exemplos concretos para explicar as novas racionalidades (NIGAM; OCASIO, 2010). Nestes processos, destaca-se a importância dos atores como agentes de mudança (MICELOTTA; LOUNSBURY; GREENWOOD, 2017). A entrada de novos players, a ascensão de atores já existentes ou, ainda, o surgimento de empreendedorismo local possibilitam perturbar 0 consenso socialmente construído, uma vez que introduz novas ideias e possibilidades de ação (GREENWOOD; SUDDABY; HININGS, 2002).

A mudança em lógicas institucionais fica, nessa perspectiva, definida predominantemente a partir da relação de externalidade entre pressões exercidas ou difundidas por aquelas lógicas e as respostas elaboradas por atores, em diferentes níveis (THORNTON; OCASIO; LOUNSBURY, 2012). Mudanças no contexto social, tecnológico ou regulatório podem desencadear a desinstitucionalização da lógica dominante. A partir disso, novas lógicas podem emergir à medida que tais eventos se tornam salientes aos atores institucionais (NIGAM; OCASIO, 2010).

Assim, consonante com o terceiro elemento da troika, tal análise além de focar no próprio fenômeno da mudança institucional também deve prestar especial atenção nos responsáveis por esses processos: os atores. As maneiras pelas quais as instituições são negociadas, interpretadas e promulgadas implicam a interação entre indivíduos (MCPHERSON; SAUDER, 2013). A agência, portanto, não deve ser visualizada apenas como culturalmente embutida na lógica institucional, mas também se torna necessário conceber 0 envolvimento desta tanto na reprodução quanto na transformação das lógicas institucionais (THORNTON; OCASIO; LOUNSBURY, 2012), uma vez que nessas, pessoas, práticas e valores estão co-implicados, cada um sendo constituído por, e através, das relações com os demais (FRIEDLAND et al., 2014).

\section{LÓGICAS, MUDANÇA E ATORES SOCIAIS}

O ator social, sua formação investida em e por um valor particular, constitui elemento essencial à operação de qualquer lógica institucional (FRIEDLAND et al., 2014). 0 modo em que esta molda o foco de atenção reflete a agência imersa, aspecto central à perspectiva da lógica, evidenciando esta como restrição para a cognição e ação individual. Entretanto, incluir a agência na concepção estática da instituição permite compreender 
simultaneamente, por meio do paradoxo da agência (SEO; CREED, 2002; GREENWOOD; HININGS, 1996), seu envolvimento na reprodução e transformação das lógicas institucionais (THORNTON; OCASIO; LOUNSBURY, 2012).

A heterogeneidade de lógicas institucionais (GREENWOOD; HININGS; WHETTEN, 2014; LOUNSBURY, 2007) se relaciona positivamente com a probabilidade de ações em direção à mudança institucional. Esse aspecto amplia o número de lógicas e quadros teóricos existentes em um dado momento histórico para a construção de modelos alternativos de arranjos institucionais que direcionam os esforços de mudança. Porém, essa relação não pode ser analisada sem a mediação dos atores sociais, responsáveis por conduzir as ações de mudança. Como resultado do desalinhamento entre as múltiplas lógicas, agentes potenciais de mudança emergem para lidar com as limitações das lógicas em ação e mobilizar a ação coletiva em direção à mudança institucional (SEO; CREED, 2002).

0 foco de atenção dos atores faz com que sejam ativadas três características: identidades sociais, objetivos e esquemas. A primeira característica corresponde às múltiplas identidades sociais e papéis que os eles possuem. Elas são empregadas como base para explicar mudança e estabilidade nas organizações no âmbito da lógica institucional, dado que nem todas as identidades sociais são igualmente acessíveis e disponíveis aos atores (THORNTON; OCASIO; LOUNSBURY, 2012). Cada identidade denota uma posição específica que pode permitir ou restringir o acesso a lógicas institucionais específicas (JANCSARY et al., 2017). Atores são mais comprometidos com identidades validadas através de trocas simbólicas com outros atores sociais em diversos contextos situacionais (THORNTON; OCASIO; LOUNSBURY, 2012). Assim, o grau em que uma identidade associada a uma lógica é adotada pelos atores influencia a forma como novas práticas são adotadas e novos vocabulários são empregados, ou seja, existem implicações importantes na forma como uma lógica é manifestada e, portanto, pode ser mudada (KYRATSIS et al., 2017; JANCSARY et al., 2017).

Igualmente, indivíduos e organizações também possuem objetivos múltiplos e discrepantes. Estes guiam a cognição e a ação em diversas ocasiões e variam no tempo, podendo moldar tanto ações correntes quanto planos futuros. A adesão aos objetivos específicos também sofre influência da conformidade com forças reguladoras ou prevenção de sanções normativas diante da não identificação com lógicas dominantes. Atores sociais, assim, buscam aprovação de outros atores com quem se relacionam, seja por meio de recompensas ou evitando punições. Por fim, os esquemas referem-se a conjuntos de regras generalizadas, definidas em relação a domínios específicos de ação ou de classes de objetivos. Eles guiam expectativas de comportamento ao ajudarem indivíduos a compreender, avaliar e agir. Constituem-se de scripts ou atividades recorrentes definidas em relação a domínios específicos de ação ou classes de objetivos (THORNTON; OCASIO; LOUNSBURY, 2012). Considerando, portanto, a importância destes elementos na promulgação e mudança de lógicas, adotamos os mesmos como categorias analíticas, conforme ilustrado no Quadro 2 a partir da relação com os dados empíricos.

A partir disso, uma importante fonte de mudança institucional é o aumento das contradições institucionais, ou seja, o desalinhamento entre arranjos sociais existentes e interesses e necessidades dos atores que constituem esses mesmos arranjos. Tal desalinhamento fornece base para o surgimento de adversários potenciais entre a população de 
atores não atendidos pela ordem existente (SEO; CREED, 2002). Em face destas contradições, indivíduos e organizações são providos de oportunidade para agência e mudanças de acordo com seus objetivos (THORNTON; OCASIO; LOUNSBURY, 2012). Assim, o suporte à nova lógica se reforça ao deslegitimar a lógica pré-existente e as identidades e práticas sociais associadas a ela (KYRATSIS et al., 2017), evidenciando que lógicas institucionais podem ser utilizadas estrategicamente para influenciar os resultados organizacionais. Elas são convertidas em ferramentas ativadas em um ambiente contestado, empregadas para dirigir a atenção, pedir considerações e moldar as decisões em detrimento de justificações post-hoc. Logo, apesar de as lógicas institucionais serem externas aos indivíduos, a sua construção, transmissão e uso estão diretamente vinculados a pessoas, dependem delas, de seus interesses, crenças e preferências (MCPHERSON; SAUDER, 2013).

À vista disso, Thornton, Ocasio e Lounsbury (2012) argumentam a necessidade de um melhor entendimento de instâncias na perspectiva da lógica em nível-micro também, pois são nesses níveis, segundo os autores, que as lógicas são traduzidas em ação, reforçando ou reconstituindo as lógicas em si. Quanto ao nível de mudança, esse gap se torna ainda mais evidente, uma vez que não foram identificados estudos em mudança de lógicas institucionais que examinam a emergência de atores nesses processos e sua relação com as novas lógicas substituídas, o que pretendemos explorar por meio dos dados a seguir.

\section{PROCEDIMENTOS METODOLÓGICOS}

Nesta pesquisa, optamos por um estudo qualitativo, por melhor captar os insights a respeito dos significados, núcleo de compreensão da perspectiva da lógica institucional (THORNTON; OCASIO; LOUNSBURY, 2012). Adotamos como estratégia metodológica o estudo de caso (YIN, 2001), cuja unidade de análise foi o Maternati - Grupo de Apoio às Mães e Gestantes. Esse Grupo tem o objetivo de proporcionar acompanhamento às gestantes, mães, pais e famílias, oferecendo um espaço de convivência e conscientização que possibilite experiência ativa e transformadora do processo, com incentivo à maior naturalidade dos vários aspectos da maternidade.

rabalhamos com o recorte seccional com avaliação longitudinal (VIEIRA, 2004), com dados coletados no ano de 2015, a partir de diversas fontes de evidências (YIN, 2001). Buscamos com isso estar mais próximos tanto das práticas quanto dos significados subjacentes a essas. Antes de dar início a esta investigação, a primeira autora realizou uma reunião com as coordenadoras do grupo, em janeiro de 2015, para maior aproximação do campo bem como consentimento da pesquisa. Sequencialmente, iniciamos paralelamente a pesquisa documental e a atuação no campo.

A pesquisa documental abrangeu uma varredura geral de documentos da área da saúde (artigos, livros, dissertações/teses, manuais), bem como uma investigação sistemática das últimas 5 décadas de quatro periódicos, a fim de delimitar as diferentes lógicas institucionais de maternidade e identificar mudanças ocorridas. Pesquisamos 3 periódicos acadêmicos: Revista de Saúde Pública (publicações de 1967 até 2015), Revista Femina (1973 a 2011), Revista Brasileira de Ginecologia e Obstetrícia (1979 a 2015); e uma revista popular, Revista Veja (1968 a 2015), resultando em um total de 295 artigos ana- 
lisados. Todas essas informações foram transpostas em uma planilha do Excel para maior confiabilidade e posterior triangulação dos dados (YIN, 2001).

Adicionalmente, demos início também a pesquisa de campo e para isso, a primeira autora do artigo realizou, por meio de inserção no Grupo, observação não-participante em todo o período de coleta de dados (ano de 2015). Esse envolvimento consistiu em acompanhamento presencial de sete tipos de atividades do Maternati, cursos de gestante, reuniões de mães, rodas de conversa, seminários, confraternizações, eventos gerais, e festas infantis, sendo que os dois primeiros foram acompanhados em duas turmas. Acompanhou-se também, virtualmente, a interação das participantes nas redes sociais (Facebook e WhatsApp). Após cada observação (virtual e presencial), os registros eram documentados em um diário de campo, resultando em 1313 páginas transcritas.

A fase de observação foi valiosa por permitir aprofundamento nas vivências da maternidade, seus simbolismos e nos atores envolvidos em todos os processos. Ela também deu base para estruturar as entrevistas que ocorreram sequencialmente, a fim de adensar em aspectos previamente identificados. Assim, após cinco meses de observação, sete entrevistas semiestruturadas foram realizadas, sendo (3) com as profissionais e (4) com mães participantes do Maternati. Realizamo-las a partir de três etapas: identificar as práticas materiais empregadas na maternidade; identificar e compreender o porquê de tais escolhas e os simbolismos implicados nestas; e identificar o que e quem contribuiu ou atrapalhou para realização da maternidade almejada. A decisão pela amostra das mães entrevistadas foi intencional e buscamos abranger diferentes períodos de participação, tipos de parto e envolvimento no grupo, sendo delimitadas pela saturação das respostas, já que novas entrevistas não iriam trazer mais nenhuma variedade significante para corroborar com a pesquisa (BAUER; AARTS, 2013). As entrevistas tiveram a média de 40 minutos e geraram 69 páginas transcritas. A participação foi de caráter voluntário e a adesão foi total.

Após coletados os dados, estes foram organizados e sistematizados com o auxílio do Software NVivo 10. Com base nas questões de pesquisa, no referencial teórico e nos documentos preliminares analisados sobre o campo, definimos as categorias analíticas. Consideramos a priori 4 variáveis iniciais. Para delimitação das lógicas institucionais, foram analisados os elementos da troika: i) práticas; ii) sujeitos; iii) objeto (vide Quadro 1); e, também, iv) os elementos contextuais.

Inicialmente, buscamos um sentido geral nos dados por meio de várias leituras do corpus de pesquisa, para uma melhor compreensão e maior familiaridade com os dados. Durante estas leituras, notas e observações, bem como códigos iniciais foram atribuídos, partindo-se das categorias. Nosso interesse central era identificar quais práticas os atores estavam promulgando, quem estava envolvido, e em quais contextos. Reconstruímos, então, historicamente a maternidade no Brasil, procurando capturar padrões e mudanças históricas ao longo do tempo e identificar quais eram as práticas comuns de maternidade, os símbolos atrelados a ela e os atores envolvidos no campo. Sobretudo, baseamo-nos nos discursos usados pelos atores para enquadrar questões e conceitos em nossos achados. Ao fazer isso, procuramos discernir padrões relacionados a vários temas que eram consistentes entre eles. Comparamos esses achados entre os períodos para identificar se havia diferença e delimitar os marcos de mudança, o que nos permitiu identificar três, separados por lógica natural antiga, lógica intervencionista e nova lógica natural de maternidade. 
Sequencialmente, a posteriori às várias releituras dos dados, fizemos um refinamento nas categorias analíticas. As práticas foram subdivididas em práticas i) naturais e ii) intervencionistas, simultaneamente com suas respectivas substâncias a partir dos discursos dos atores. Já quanto aos sujeitos, identificados os atores-chave mais citados e/ou apontados como essenciais à promulgação das práticas naturais na nova lógica de maternidade, esses foram analisados a partir de três subcategorias, conforme Thornton, Ocasio e Lounsbury (2012), identidades e papéis sociais, objetivos e esquemas (vide Quadro 2). Focamos em fragmentos dos dados que se relacionavam especificamente com os papéis sociais que eles assumiam na nova lógica, qual sua importância/relevância para que ela fosse encarnada, os interesses e objetivos desses atores no campo, quais atividades desempenhavam, e quais normativas, protocolos e intercambialidade a outros textos e atores (OMS, ANS, Anvisa...) eles seguiam e/ou representavam.

A partir disso, nosso objetivo, então, foi estabelecer conexões conceituais entre as categorias que permitissem delimitar dimensões teóricas subjacentes às elas, na tentativa de entender como as diferentes categorias se encaixavam em um quadro abrangente e coerente sobre as mudanças das lógicas de maternidade no Brasil. Nos achados que se seguem, e são melhor detalhados nas próximas seções, procuramos intercalar nossa análise com trechos salientes coletados dos dados empíricos a fim de ilustrar nossa interpretação dos dados, e evidenciar o processo analítico construído (vide trechos expostos ao longo da seção de resultados e na coluna evidências do Quadro 2).

\section{RESULTADOS}

Conforme exposto anteriormente, a maternidade no Brasil se configura pelo modelo tecnocrático dominante, marcado pela lógica intervencionista, com alta incidência de cesárea (VALADARES, 2017), baixo índice de amamentação, predomínio de aleitamento artificial (SUSIN; GIUGLIANI; KUMMER, 2005) e grande dependência de aparato técnico (RATTNER, 2009). No entanto, diante do afastamento cada vez maior do modelo preconizado pela OMS (1996), e de evidências relacionando maiores taxas de morbidade e mortalidade materna e neonatal com a incidência de cesárea (FAÚNDES; CECATTI, 1991; VILLAR et al., 2006), a partir das décadas de 1980 e 1990, uma série de eventos disruptivos preocupados com a intensa medicalização do nascimento passaram a minar a lógica intervencionista. Estes reivindicavam a preservação da normalidade do parto e menor intervenção, pautando-se em valores do que é natural, fisiológico e instintivo ao ser humano, portanto, saudável e que permite o encontro com a essência da pessoa. Emerge, então, o movimento pela humanização da maternidade, com forte atuação de grupos organizados por mulheres (DINIZ, 2005; BRASIL, 2001; JONES, 2007).

Em 1984 foi instituído o PAISM, Programa de Assistência Integral à Saúde da Mulher. Sequencialmente, diversas organizações foram criadas no intuito de resgatar o nascimento humanizado e as condutas e posturas face ao parto (ReHuNa - Rede pela Humanização do Parto e Nascimento; Relacahupan - Rede Latino-americana e do Caribe para a Humanização do Parto e Nascimento; Rede Gapp - Grupos Apoiados pela Parto do Princípio). Esses e outros movimentos de mulheres vêm atuando e cobrando atuação do Ministério de Saúde para melhorias, resultando em ações do mesmo (BRASIL, 2001; JONES, 
2007), bem como se apoiando em diretrizes da OMS e modelos obstétricos humanizados de outros países como Inglaterra e Holanda.

Logo, com base em nossos dados, observamos que a maternidade no Brasil é configurada por três períodos marcantes, cada um com sua respectiva lógica dominante. O Quadro 1 ilustra cada uma das lógicas, caracterizadas a partir de seus elementos constituintes, sujeito, prática e objeto (FRIEDLAND et al., 2014). Além dos dois primeiros, discutidos a partir dos dados secundários, a configuração de uma nova lógica, portanto - terceiro estágio - e foco deste artigo, ocorre concomitantemente ao resgate de práticas comuns ao período anterior à lógica intervencionista. Em termos organizacionais, ela se dá principalmente pela constituição de grupos de profissionais e mulheres reunidas em torno da adoção e difusão de práticas, técnicas e conhecimentos que tentam - principalmente no Brasil - reverter a forte inclinação ao parto por cesárea e maternidade intervencionista. Um desses grupos, cuja atuação foi foco de nossa investigação, é o Maternati.

Quadro 1 - Lógicas Institucionais de Maternidade

\begin{tabular}{|c|c|c|c|}
\hline $\begin{array}{l}\text { Lógica de } \\
\text { Maternidade }\end{array}$ & Sujeito & Prática & Objeto \\
\hline \multirow{4}{*}{$\begin{array}{l}\text { Lógica Natural } \\
\text { (Anterior dec. } \\
\text { 1970) }\end{array}$} & Mulher como protagonista & Parto Normal & $\begin{array}{l}\text { Nascimento como um evento } \\
\text { natural }\end{array}$ \\
\hline & Ofício das parteiras & Parto Domiciliar & $\begin{array}{l}\text { Saber empírico, tradicional, } \\
\text { transmitido de geração em } \\
\text { geração }\end{array}$ \\
\hline & $\begin{array}{l}\text { Rede das mulheres (coma- } \\
\text { dres) }\end{array}$ & Aleitamento Materno & $\begin{array}{l}\text { Maternidade como função } \\
\text { exclusiva da mulher }\end{array}$ \\
\hline & & Fraldas de pano & Era como tinha que ser \\
\hline \multirow{7}{*}{$\begin{array}{l}\text { Lógica Interven- } \\
\text { cionista (Dec. } \\
1970 \text { - Atual) }\end{array}$} & Mulher como paciente & Parto como evento médico & $\begin{array}{l}\text { Confiança na ciência e no co- } \\
\text { nhecimento técnico específico }\end{array}$ \\
\hline & Médico como protagonista & Cesárea eletiva & $\begin{array}{l}\text { Comodidade e facilidade em } \\
\text { planejar o parto, alinhar com } \\
\text { vida profissional }\end{array}$ \\
\hline & Ofício médico & $\begin{array}{l}\text { Uso de técnicas anestésicas e } \\
\text { aparato médico }\end{array}$ & $\begin{array}{l}\text { Crença que a tecnologia é } \\
\text { mais segura e confiável }\end{array}$ \\
\hline & Hospitais e maternidades & Parto hospitalar & $\begin{array}{l}\text { Controle da natureza em } \\
\text { benefício do ser humano }\end{array}$ \\
\hline & Predomínio da tecnologia & $\begin{array}{l}\text { Leite artificial e controle do } \\
\text { horário de amamentação }\end{array}$ & $\begin{array}{l}\text { Crença na superioridade do } \\
\text { leite artificial, visão de bebê } \\
\text { saudável como bebê gordinho }\end{array}$ \\
\hline & Babás/creches & $\begin{array}{l}\text { Introdução alimentar via } \\
\text { spoon-feeding }\end{array}$ & $\begin{array}{l}\text { Maternidade como um dos } \\
\text { papéis desempenhados pela } \\
\text { mulher }\end{array}$ \\
\hline & & $\begin{array}{l}\text { Método do choro controlado/ } \\
\text { extinção }\end{array}$ & $\begin{array}{l}\text { Praticidade (alinhar a ma- } \\
\text { ternidade a outros papéis da } \\
\text { mulher) }\end{array}$ \\
\hline
\end{tabular}




\begin{tabular}{|c|c|c|c|}
\hline $\begin{array}{l}\text { Lógica de } \\
\text { Maternidade }\end{array}$ & Sujeito & Prática & Objeto \\
\hline \multirow{9}{*}{$\begin{array}{l}\text { Nova Lógica } \\
\text { Natural (Dec. } \\
1980 \text { - Atual) }\end{array}$} & Mulher como protagonista & Parto Natural & $\begin{array}{l}\text { Nascimento como um evento } \\
\text { natural }\end{array}$ \\
\hline & $\begin{array}{l}\text { Ofício médico e/ou da enfer- } \\
\text { meira obstétrica }\end{array}$ & Parto hospitalar ou domiciliar & $\begin{array}{l}\text { Confiança na medicina basea- } \\
\text { da em evidências }\end{array}$ \\
\hline & $\begin{array}{l}\text { Movimento humanização do } \\
\text { parto e nascimento }\end{array}$ & $\begin{array}{l}\text { Aleitamento materno em livre } \\
\text { demanda }\end{array}$ & $\begin{array}{l}\text { Empoderamento feminino/res- } \\
\text { peito às escolhas e vontades } \\
\text { da mulher }\end{array}$ \\
\hline & $\begin{array}{l}\text { Grupos organizados por } \\
\text { mulheres }\end{array}$ & Fraldas de pano modernas & Mais saudável \\
\hline & $\begin{array}{l}\text { Ações governamentais de } \\
\text { incentivo à normalidade do } \\
\text { parto }\end{array}$ & $\begin{array}{l}\text { Introdução alimentar pelo } \\
\text { método BLW }\end{array}$ & $\begin{array}{l}\text { Próprio da natureza - além do } \\
\text { controle humano }\end{array}$ \\
\hline & Doula & Criação com apego & Contato/proximidade \\
\hline & $\begin{array}{l}\text { Fonoaudióloga/ aconselha- } \\
\text { mento de amamentação }\end{array}$ & $\begin{array}{l}\text { Preferência por tratamentos } \\
\text { naturais e homeopáticos para } \\
\text { enfermidades }\end{array}$ & $\begin{array}{l}\text { Possibilita transformação/rup- } \\
\text { tura (mulher se torna mãe) }\end{array}$ \\
\hline & Creche parental & Uso de sling & $\begin{array}{l}\text { Condição fisiológica e instinti- } \\
\text { va (sabedoria própria) }\end{array}$ \\
\hline & Casas de parto & & $\begin{array}{l}\text { Encontro com a essência da } \\
\text { mulher }\end{array}$ \\
\hline
\end{tabular}

Fonte: Elaborado pelos autores com base nos dados obtidos com a pesquisa.

Observamos nesse grupo específico (mas o mesmo padrão é evidenciado em outros casos similares), o resgate de práticas outrora dominantes, a busca por parto normal, muitas vezes domiciliar, o aleitamento materno, e a dedicação exclusiva à maternidade (mesmo que, em alguns casos, momentâneos aos primeiros anos da criança). Observamos também uma criação priorizando maior contato entre mãe-bebê, livre de intervenções, como a criação com apego e o método de introdução alimentar BLW. Estas práticas se alicerçam em valores do que é natural, próprio da natureza humana ("porque eu acho que é assim que tem que ser" - Entrevista Mãe 3; "o parto normal nada mais é do que a vida seguindo seu curso naturalmente" - Relato de parto Mãe 5), fazem parte da sabedoria própria e instintiva do ser humano ("[...] o BLW, que é deixar a criança seguir o instinto dela - Entrevista Mãe 2; "sentia que eu havia perdido qualquer controle sobre meu corpo, mas, ao mesmo tempo, estava tudo sob controle" - Relato de Parto Mãe 6) e, portanto, mais saudável ("Eu acredito que tudo que é da natureza concorre para o bem do ser humano" - Entrevista Mãe 1) e que leva ao encontro com a essência da pessoa ("abri mão da vida profissional... eu acho que a minha profissão é essa [ser mãe], eu vejo assim, eu me encontrei" - Entrevista Mãe 3)

Entretanto, a retomada da lógica natural de maternidade não significa uma mera repetição da antiga lógica natural, que retornaria idêntica. Além de mudanças no objeto conforme Quadro 1, as mudanças contextuais foram aos poucos inviabilizando as práticas iguais à época. Por exemplo, a rede de mulheres que se formava antigamente, considerada importante para a maternidade natural, já não era possível com a diminuição do tamanho da família, entrada da mulher no mercado de trabalho, e influência de experiência de outras mulheres com a lógica intervencionista. Com isso, na visão das integrantes do grupo, a 
maternidade se tornou um exercício solitário, com ausência desse apoio feminino. A participação em grupos de apoio, assim, é vista como forma de resgatar essa prática, já que possibilita a construção da rede com outras mulheres (não mais com a família), conforme relato:

E era uma rede de mulheres se ajudando. Então, a minha vó tinha irmã, cunhadas, vizinhas e todo mundo que ia lá pra cozinhar, cuidar da casa, dos filhos pra que ela pudesse ficar sete dias na cama, com o filho dela. Hoje em dia não é isso que acontece. Geralmente, a nossa geração tem mães que trabalham ou estudam ou fazem alguma coisa. Não é raro as mulheres saírem da maternidade, chegarem em casa e não ter ninguém [ [...]] então é muito comum que as mulheres cheguem em casa com a criança recém-nascida e fiquem sozinhas. Não tem uma rede de apoio como tinha antigamente, que todo mundo ajudava todo mundo e eu acho que o Maternati serve como isso, como uma rede de apoio (Entrevista mãe 1).

Adicionalmente, é evidente no movimento pela humanização do parto e do nascimento o entendimento da maternidade natural, principalmente do parto normal e da amamentação, como uma "luta", algo pelo qual se deve "batalhar". Isso decorre, na visão do grupo, da contradição entre a lógica natural e a lógica intervencionista predominante no país, conforme trecho abaixo:

No Brasil a gente tem a questão da cultura cesarista, que é o primeiro país no ranking mundial de cesáreas no mundo. Então, pra você conseguir ter um parto natural no Brasil você tem que ter muito apoio, inclusive tem que às vezes até gastar muito dinheiro para conseguir ter um parto, porque os médicos que deveriam ser aqueles que mais te instruiriam no melhor para a saúde sua e do seu bebê, não fazem isso, têm muitos interesses por debaixo, tanto financeiros, quanto outros. Então a gente precisa de um apoio extra (Entrevista mãe 2).

Logo, por estarem inseridas em uma luta de lógicas institucionais contraditórias (FRIEDLAND; ALFORD, 1991), percebe-se entre o grupo, a difusão de todo um preparo e adoção de estratégias para que a busca pelo tipo de parto e criação dos filhos desejados seja possível. Estes são propiciados e difundidos por novos atores que emergem concomitante à mudança de lógica e que reforçam a sua institucionalização entre o campo da maternidade. O Quadro 2 ilustra alguns dos principais atores que emergiram, a partir de suas identidades sociais, objetivos e esquemas, e evidências coletadas que demonstram sua importância na emergência da nova lógica natural. 
Quadro 2 - Emergência de novos atores no campo da maternidade

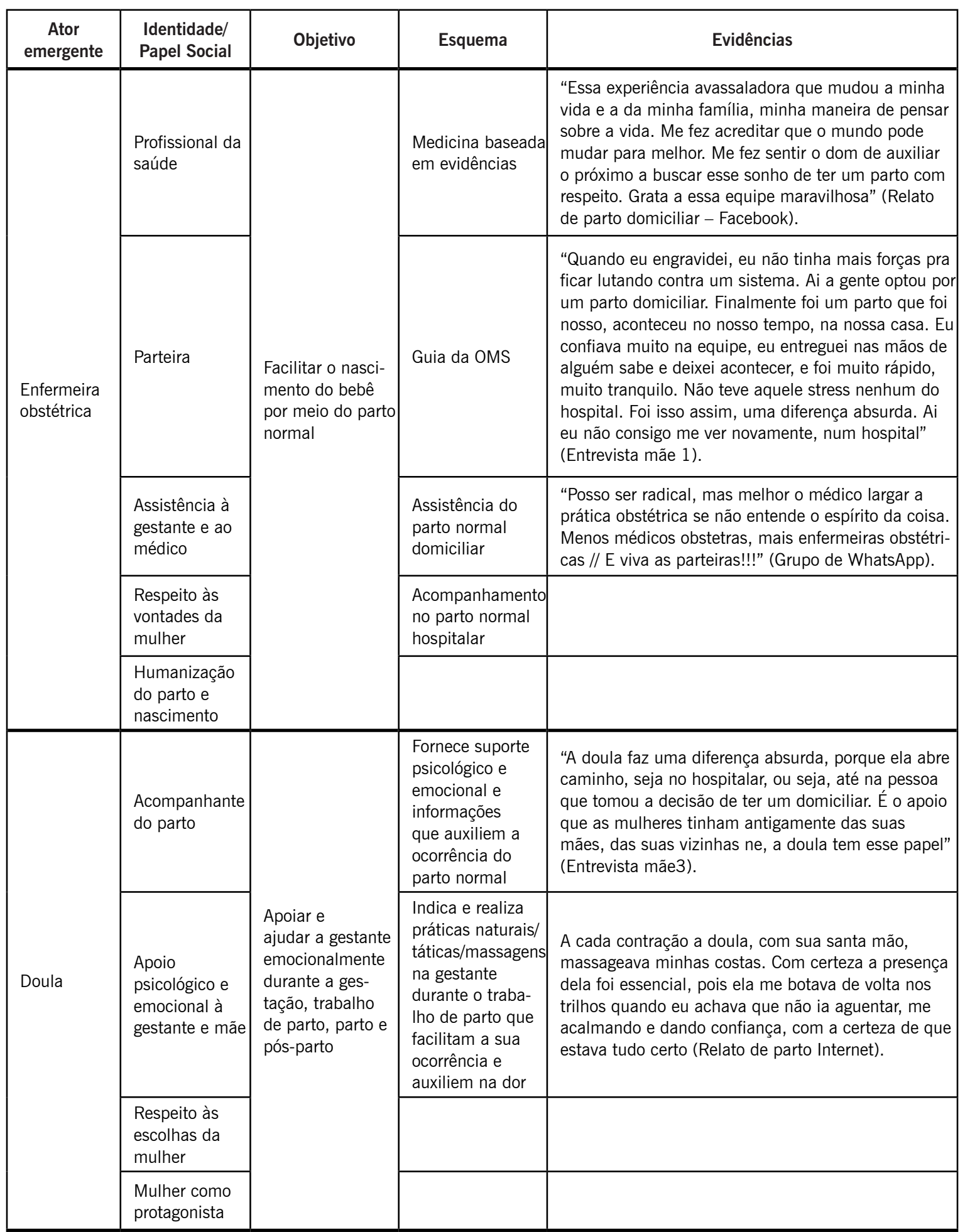




\begin{tabular}{|c|c|c|c|c|}
\hline $\begin{array}{l}\text { Ator emer- } \\
\text { gente }\end{array}$ & $\begin{array}{l}\text { Identidade/ } \\
\text { Papel Social }\end{array}$ & Objetivo & Esquema & Evidências \\
\hline \multirow{6}{*}{$\begin{array}{l}\text { Grupo de } \\
\text { Apoio }\end{array}$} & Mulheres & $\begin{array}{l}\text { Proporcionar } \\
\text { apoio, formação e } \\
\text { informação sobre } \\
\text { práticas naturais, } \\
\text { cursos de preparo } \\
\text { físico e emocional }\end{array}$ & $\begin{array}{l}\text { Realização de } \\
\text { encontros, rodas } \\
\text { de conversa, } \\
\text { oficinas }\end{array}$ & $\begin{array}{l}\text { "Chegamos a um grupo chamado Maternati, nos } \\
\text { encontros do grupo uma troca intensa das mais } \\
\text { diversas experiências de parto. Comecei a me dar } \\
\text { conta que para ter um parto natural precisaria buscar } \\
\text { uma equipe humanizada (...) E a partir daí foram } \\
\text { diversas consultas, afinando todos os pontos, muitas } \\
\text { conversas com a minha doula para o preparo psicoló- } \\
\text { gico, e muito preparo físico também (hidroginástica, } \\
\text { exercícios de loga, exercícios Kegel) (Relato de parto } \\
\text { Internet). }\end{array}$ \\
\hline & Mães & $\begin{array}{l}\text { Conscientizar as } \\
\text { mulheres sobre } \\
\text { seus direitos } \\
\text { de escolha, } \\
\text { necessidade de } \\
\text { mudanças no } \\
\text { sistema obstétrico } \\
\text { atual }\end{array}$ & $\begin{array}{l}\text { Divulgação de } \\
\text { práticas naturais } \\
\text { e auxílio em } \\
\text { dificuldades de } \\
\text { amamentação, } \\
\text { parto e criação } \\
\text { dos filhos }\end{array}$ & $\begin{array}{l}\text { Fomos buscar apoio ao parto Natural em Maringá, } \\
\text { até que encontramos o grupo Maternati e come- } \\
\text { çamos a participar das rodas de conversa onde } \\
\text { conhecemos a (Doula) que nos incentivou mais ainda } \\
\text { (Relato de parto) }\end{array}$ \\
\hline & $\begin{array}{l}\text { Profissionais da } \\
\text { saúde }\end{array}$ & $\begin{array}{l}\text { Erradicar a violên- } \\
\text { cia obstétrica }\end{array}$ & & $\begin{array}{l}\text { "Então quando elas falam em qualquer outro lugar } \\
\text { que elas querem isso, as pessoas olham de cara feia, } \\
\text { falam que elas não vão conseguir, onde já se viu } \\
\text { em pleno século XXI você vai sofrer [...] Então um } \\
\text { espaço em comum, onde elas podem ser aceitas por } \\
\text { elas mesmas, pela gente, onde não tem essa crítica } \\
\text { imposta, numa rejeição [...] então isso é muito } \\
\text { necessário, porque é um momento muito desampara- } \\
\text { dor da sociedade" (Entrevista psicológica). }\end{array}$ \\
\hline & $\begin{array}{l}\text { Empoderamen- } \\
\text { to feminino } \\
\text { para que lutem } \\
\text { por suas } \\
\text { escolhas }\end{array}$ & $\begin{array}{l}\text { Facilitar a mater- } \\
\text { nidade natural }\end{array}$ & $\begin{array}{l}\text { Elo entre os } \\
\text { demais atores, } \\
\text { difundindo-os } \\
\text { simultaneamente } \\
\text { (doula, creche, } \\
\text { enfermeira, } \\
\text { atividades físicas) }\end{array}$ & $\begin{array}{l}\text { "O que as mães falam sobre o Maternati, sobre os } \\
\text { grupos é de um lugar que elas aprenderam, em } \\
\text { que elas conseguiram um empoderamento, que } \\
\text { elas conseguiram informações e gente pra lutar" } \\
\text { (Entrevista mãe1). }\end{array}$ \\
\hline & & & & $\begin{array}{l}\text { "Vocês abriram as portas para um mundo novo, de } \\
\text { apego, de livre demanda, de tantas coisas lindas que } \\
\text { sem vocês talvez eu teria feito tudo diferente" (Grupo } \\
\text { de WhatsApp mãe). }\end{array}$ \\
\hline & & & & $\begin{array}{l}\text { "Pra mim [o grupo] foi mais pra adquirir informações } \\
\text { e apoio assim, sabe? Eu já não tinha muito apoio da } \\
\text { família, o marido era meio assim. Então eu precisava } \\
\text { de mais gente pra me apoiar e dizer que era possível } \\
\text { essa minha vontade, que pra muitos é loucura. Um } \\
\text { apoio que o grupo todo aqui me deu, as mães que eu } \\
\text { conheci, as doulas" (Entrevista mãe 4). }\end{array}$ \\
\hline
\end{tabular}




\begin{tabular}{|c|c|c|c|c|}
\hline $\begin{array}{l}\text { Ator emer- } \\
\text { gente }\end{array}$ & $\begin{array}{l}\text { Identidade/ } \\
\text { Papel Social }\end{array}$ & Objetivo & Esquema & Evidências \\
\hline \multirow{6}{*}{$\begin{array}{l}\text { Movimento } \\
\text { de mulheres }\end{array}$} & Mães & $\begin{array}{l}\text { Incentivar e } \\
\text { propagar maior } \\
\text { incidência de } \\
\text { parto natural, } \\
\text { humanização do } \\
\text { parto, empodera- } \\
\text { mento da mulher }\end{array}$ & $\begin{array}{l}\text { Formação e } \\
\text { difusão de grupos } \\
\text { sociais/ONGS }\end{array}$ & $\begin{array}{l}\text { "Essa relação (medidas da ANS) só saiu porque } \\
\text { houve uma denúncia do grupo de mulheres sobre } \\
\text { a taxa abusiva das cesáreas. Elas denunciaram } \\
\text { no ministério Público por isso que a ANS mudou" } \\
\text { (Grupo de Gestantes - Psicóloga) }\end{array}$ \\
\hline & Gestantes & $\begin{array}{l}\text { Denunciar violên- } \\
\text { cia obstétrica }\end{array}$ & $\begin{array}{l}\text { Realização de } \\
\text { eventos, passea- } \\
\text { tas de divulgação } \\
\text { e conscientização }\end{array}$ & $\begin{array}{l}\text { Em 2006, a Parto do Princípio elaborou um } \\
\text { dossiê sobre o atendimento ao parto no Brasil. } \\
\text { O documento foi entregue ao Ministério Público } \\
\text { Federal, solicitando sua atuação diante do cenário } \\
\text { preocupante de abuso de cesáreas, em especial no } \\
\text { setor suplementar de saúde. Com base no dossiê, } \\
\text { uma Ação Civil Pública foi ajuizada em } 2010 \text { (Site } \\
\text { da Parto do Princípio). }\end{array}$ \\
\hline & $\begin{array}{l}\text { Profissionais da } \\
\text { saúde }\end{array}$ & $\begin{array}{l}\text { Pleitear por maio- } \\
\text { res iniciativas } \\
\text { governamentais }\end{array}$ & $\begin{array}{l}\text { Realização de } \\
\text { abaixo-assinados, } \\
\text { denúncias e } \\
\text { cobranças } \\
\text { de iniciativas } \\
\text { governamentais e } \\
\text { fiscalizadoras }\end{array}$ & \\
\hline & $\begin{array}{l}\text { Movimento } \\
\text { feminista }\end{array}$ & & & \\
\hline & $\begin{array}{l}\text { Empoderamen- } \\
\text { to feminino }\end{array}$ & & & \\
\hline & $\begin{array}{l}\text { Humanização } \\
\text { do parto e } \\
\text { nascimento }\end{array}$ & & & \\
\hline \multirow{5}{*}{$\begin{array}{l}\text { Fonoaudiólo- } \\
\text { ga / Grupos } \\
\text { de apoio a } \\
\text { amamenta- } \\
\text { ção }\end{array}$} & Fonoaudióloga & $\begin{array}{l}\text { Divulgar a prática } \\
\text { da amamentação } \\
\text { em livre demanda }\end{array}$ & $\begin{array}{l}\text { Assistência às } \\
\text { mães diante de } \\
\text { dificuldades de } \\
\text { amamentar }\end{array}$ & $\begin{array}{l}\text { "E assim, eu tive um não venci sozinha, teve pessoas } \\
\text { que eu devo a minha vitória, principalmente na } \\
\text { amamentação" (Entrevista Mãe 2). }\end{array}$ \\
\hline & $\begin{array}{l}\text { Mães que } \\
\text { amamentaram }\end{array}$ & $\begin{array}{l}\text { Auxiliar mães } \\
\text { com dificuldade } \\
\text { em amamentar }\end{array}$ & $\begin{array}{l}\text { Instrução de } \\
\text { técnicas que auxi- } \\
\text { liem e facilitem a } \\
\text { amamentação }\end{array}$ & $\begin{array}{l}\text { "E graças a Deus, cheguei a um grupo de apoio a } \\
\text { mães! Foi minha salvação! Várias mães me ajuda- } \\
\text { ram" (Relato de amamentação Internet). }\end{array}$ \\
\hline & $\begin{array}{l}\text { Amamentação } \\
\text { como mais } \\
\text { saudável, } \\
\text { benéfico }\end{array}$ & $\begin{array}{l}\text { Conscientizar so- } \\
\text { bre a importância } \\
\text { da amamentação } \\
\text { exclusiva e em } \\
\text { livre demanda }\end{array}$ & $\begin{array}{l}\text { Apoio e incentivo } \\
\text { emocional e } \\
\text { psicológico para } \\
\text { persistir na } \\
\text { amamentação }\end{array}$ & $\begin{array}{l}\text { "Obrigada ao Banco de Leite, às doulas lindas do } \\
\text { Maternati, ao IC Vacinas, à enfermeira ---, às amigas } \\
\text { do grupo de mães pelo apoio, socorro e informações } \\
\text { corretas. Sem vocês seria muito mais difícil. Com } \\
\text { vocês, me fortaleci" (Relato de amamentação } \\
\text { Internet). }\end{array}$ \\
\hline & $\begin{array}{l}\text { Vínculo mãe e } \\
\text { bebê }\end{array}$ & & & \\
\hline & Se sentir mãe & & & \\
\hline
\end{tabular}




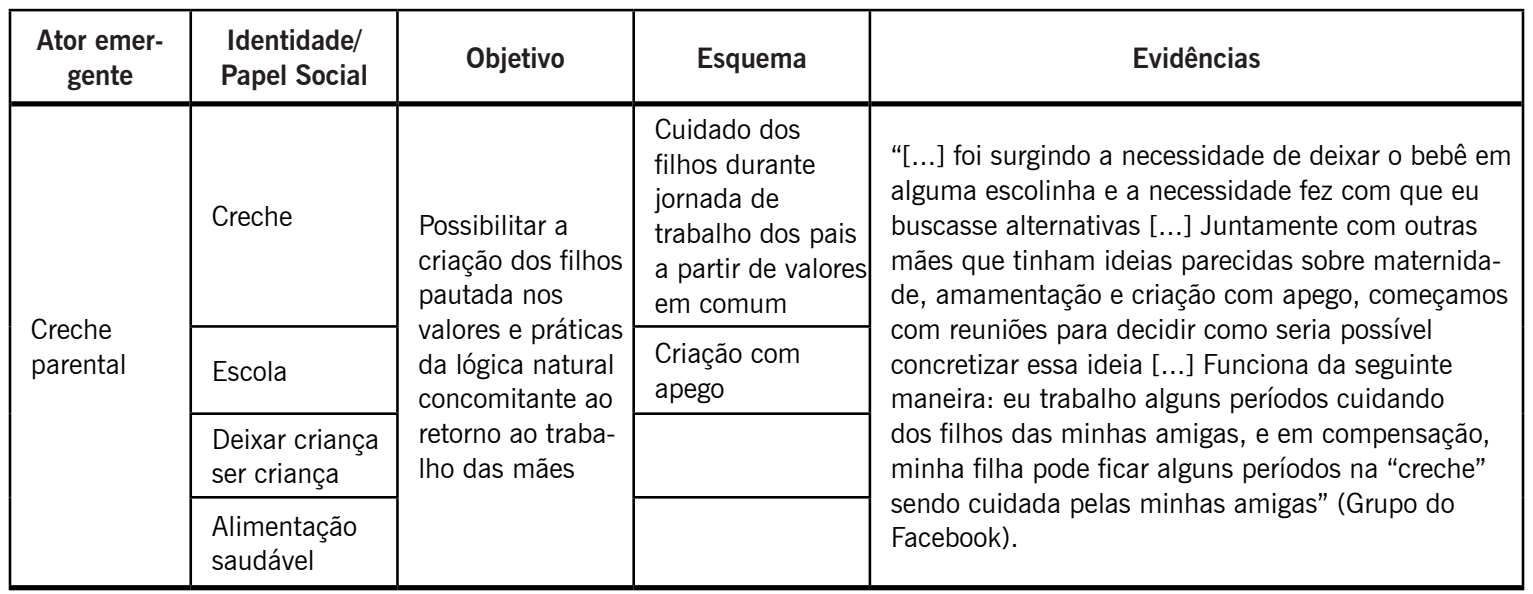

Fonte: Elaborado pelos autores com base nos dados obtidos com a pesquisa.

Inicialmente, essa preparação abrange a busca e troca por informações, práticas, experiências e indicações de profissionais humanizados que possibilitem a maternidade natural. Para isso, destaca-se a importância dos grupos de apoio/redes de mulheres que reúnem profissionais da saúde, doulas, gestantes e mães. Envolve também a preparação física para o parto, para o que são indicadas práticas como yoga, pilates, exercícios de Kegel e hidroginástica, com turmas e exercícios específicos, conforme observado nas evidências do Quadro 2. A busca por conhecimento, também indicado, se pauta principalmente no estudo da fisiologia do corpo e é propiciada pela participação em cursos específicos de gestantes e convívio de mães, como ofertados pelo Maternati, participação em outras atividades do grupo, leitura dos livros, artigos e discussões nas redes sociais e também no acompanhamento com doula. Ainda, destacam-se as figuras da doula e da enfermeira obstétrica como facilitadoras do parto normal e da fonoaudióloga como facilitadora da amamentação, que orientam e auxiliam na assistência à maternidade pautada em valores naturais e humanizados.

A participação nos grupos e redes sociais, por sua vez, também propicia que relatos e experiências das mulheres que aderiram a essas práticas, e contaram com a ajuda desses atores emergentes, sejam difundidas para outras pessoas. Com isso, a indicação dos mesmos bem como o reforço da importância de suas respectivas contratações na gestação, parto e maternidade, contribui para a legitimação da nova lógica, reforçando a sua influência expandida recursivamente no campo. Por conseguinte, conforme observado no Quadro 2, estes atores, com diferentes identidades e papéis sociais, atuam em comum com o objetivo de possibilitar uma maternidade natural, seja na assistência, no aconselhamento ou na instrução de conhecimentos, atividades e experiências. Suas respectivas atuações permitem a promulgação de práticas naturais desejadas pelas mulheres, e suportadas por esquemas e diretrizes validadas por outros órgãos e contextos, como OMS e Ministério da Saúde.

\section{DISCUSSÃO E CONCLUSÃO}

Nossa pesquisa contribui com a perspectiva da lógica institucional ao mostrar as relações dinâmicas entre condições contextuais e atores no suporte e geração de mudança institucional. A partir de elementos contextuais específicos, contradições em lógicas institu- 
cionais se tornam salientes e são percebidas pelos atores, o que, por sua vez, desencadeia processos de teorização e representação, tornando propícia a sustentação para mudança de lógicas dominantes. Apesar de estudos já demonstrarem a ligação entre lógicas institucionais, mudança, contexto social e atores (LOUNSBURY; BOXENBAUM, 2013; SEO; CREED, 2002; GREENWOOD; SUDDABY; HININGS, 2002), este estudo contribui ao dar foco na emergência de novos atores como condutores de mudança em lógicas, possibilitando a sua expansão recursiva no campo.

À vista dos questionamentos propostos no artigo, o primeiro possibilitou verificar um dos princípios da perspectiva da lógica institucional: seu caráter historicamente contingente (THORNTON; OCASIO; LOUNSBURY, 2012). As lógicas institucionais de maternidade identificadas neste estudo variaram ao longo do tempo, tendo suas dominâncias alteradas, sendo que tais mudanças acompanharam também eventos históricos. A partir de elementos contextuais em que as lógicas institucionais se encontravam inseridas, modificações em suas práticas e valores puderam ser observadas, sendo identificados dois tipos de mudança em lógica institucional: a substituição (THORNTON; OCASIO; LOUNSBURY, 2012), com subsequente dominância da lógica intervencionista e, posteriormente - foco do artigo -, a retomada (LOK, 2010), a observação de que a antiga lógica natural está sendo resgatada localmente por grupos de mulheres (como aquele por nós estudado) e pelo movimento de humanização do parto e nascimento, de modo geral.

Com base nos dados empíricos, observamos que a retomada da lógica natural se tornou favorável a partir de contradições evidenciadas na lógica pré-existente (THORNTON; OCASIO; LOUNSBURY, 2012), fundamentas em elementos contextuais à época. Acreditamos que esse achado tem importante implicação teórica ao demonstrar que a atenção a eventos específicos em diversos âmbitos (social, estatal, profissional e mercadológico), tais como altos índices de mortalidade materna e neonatal, excesso de tecnificação e dificuldade de um parto humanizado com o protagonismo da mulher, dentre outros elementos, influenciaram a percepção dos atores em conceber o atual cenário como incoerente, e possibilitaram o desalinhamento entre a lógica dominante e as identidades e objetivos dos atores (LOK, 2010; KYRATSIS et al., 2017); o que, por sua vez, direcionou a emergência de uma nova lógica (NIGAM; OCASIO, 2010) de maternidade.

Entretanto, evidenciamos ainda, que as mudanças contextuais que foram ocorrendo ao longo dos anos, não apenas salientaram contradições entre arranjos vigentes e interesses dos atores, como também inviabilizaram a retomada da nova lógica natural de forma idêntica à antiga lógica. Em função disso, observou-se que a transição para a nova lógica de maternidade se tornou possível a partir da sustentação de estratégias que auxiliaram sua adoção, promulgadas por novos atores. Ao destacarmos isso, nós redirecionamos a atenção para atores emergentes como condutores de mudança de lógica, respondendo ao segundo questionamento proposto e trazendo como implicação o papel da agência na perspectiva da lógica.

A impossibilidade da formação de redes de mulheres, por exemplo, levou a formação de grupos de apoio; já a diminuição da atuação de parteiras, concomitante ao desejo pelo parto domiciliar, e a importância atribuída ao conhecimento científico proporcionou a formação de equipes interdisciplinares (enfermeira obstétrica, neonatal e doula) que as substituíssem. Ainda, de modo específico, a enfermeira obstétrica, que já era atuante na 
lógica intervencionista, emerge na nova lógica natural na figura da parteira, representando, simultaneamente, a cientificidade valorizada na lógica intervencionista - conhecimento obstétrico - e o ofício outrora realizado na lógica natural - assistir o parto -, cujo protagonismo é da parturiente.

Assim, percebe-se que a mudança para uma nova lógica, não ocorreu como uma ruptura radical. A retomada da nova lógica decorreu da teorização dos atores de dimensões da lógica, consistentes com representações concretas de exemplos do campo da maternidade de outros cenários - período anterior à lógica intervencionista e modelos obstétricos de outros países -, bem como características específicas atuais do campo - diretrizes da OMS, índices de mortalidade e morbidade, e mesmo aspectos positivos avaliados do arranjo atual, como o avanço científico e medicina baseada em evidências. 0 resultado da mudança - a nova lógica -, dessa forma, se relaciona com condições iniciais de lógicas anteriores (WAEGER; WEBER, 2019). Logo, à medida que os atores sociais compreendem como diferentes lógicas se reforçam, a recombinação de novas práticas mescladas é favorecida, gerando um conjunto coerente de prescrições e valores para o funcionamento organizacional (RAMUS; VACCARO; BRUSONI, 2017).

Esses, dentre outros casos observados, implicam que a emergência de novos atores de mudança possibilitou e reforçou a expansão da nova lógica no campo, levando a sua institucionalização. Observação que remete ao terceiro questionamento proposto. A identificação dos atores para com a nova lógica ocorreu por meio de interações sociais, que ao serem difundidas no grupo, possibilitaram a caracterização e sua diferenciação em relação a outras lógicas. Dessas relações surgiram agentes de mudança que sustentam esses processos à medida que desafiam a legitimidade existente, justificam o cenário para modos alternativos e mobilizam esforços para outras lógicas. Concomitantemente, geram a difusão e institucionalização da mesma no campo em que atuam (COLYVAS; JONSSON, 2011).

Por conseguinte, baseados em Greenwood, Suddaby e Hinings (2002), nós realçamos o papel da emergência de atores como condutores da mudança, porquanto ao mesmo tempo em que eles emergiram no campo da maternidade, também reforçaram e direcionaram a sua institucionalização, difundindo a nova lógica institucional. A análise histórica da maternidade possibilita verificar a capacidade dos agentes de lidar com diferentes lógicas institucionais, inseridas em ambientes contraditórios, mobilizando recursos destes para legitimar e apoiar seus esforços de mudança (SEO; CREED, 2002). Compreende-se, assim, a relação entre a lógica institucional e os atores que a promulgam e direcionam ações de mudança de acordo com o contexto em que se inserem.

Adicionalmente, destacamos que nosso estudo também apresenta importante ramificação prática. Dado o interesse em reverter a alta incidência de cesarianas no país e realizar mudanças que melhorem efetivamente o sistema de saúde brasileiro, é crítico que se tenha melhor compreensão da lógica de maternidade que caracteriza o cenário desejado, bem como das relações dinâmicas entre os atores, seus interesses e identidades, e elementos contextuais limitantes. A discussão proposta neste artigo fornece, portanto, base para reforço e institucionalização de práticas preconizadas por órgãos públicos e privados que atuam para contornar problemas de saúde brasileira.

Finalmente, o contexto da maternidade no Brasil, com as mudanças ao longo da história, e no momento atual em destaque pela dominância peculiar da lógica intervencio- 
nista e pelo crescente movimento de humanização do parto e do nascimento, propiciou a observação desses fenômenos, restando como sugestão para investigação futura a análise de outros campos onde se verifiquem fenômenos similares aos aqui descritos.

\section{REFERÊNCIAS}

ALMANDOZ, J. Founding teams as carriers of competing logics when institutional forces predict banks' risk exposure. Administrative Science Quarterly, v. 59, n. 3, p. 442-473, 2014.

ANS publica resolução para estimular parto normal na saúde suplementar. Agência Nacional de Saúde Suplementar. Rio de Janeiro, 06 Jan. 2015. Disponível em: http://www.ans.gov. br/aans/noticias-ans/consumidor/2718-ministerio-da-saude-e-ans-publicam-resolucao-para-estimular-parto-normal-na-saude-suplementar. Acesso em: 02 dez. 2016.

ANSARI, S.; WIJEN, F.; GRAY, B. Constructing a climate change logic: an institutional perspective on the "tragedy of the commons". Organization Science, v. 24, n. 4, p. 1014-1040, 2013.

BATTILANA, J.; DORADO, S. Building sustainable hybrid organizations: the case of commercial microfinance organizations. Academy of Management Journal, v.53, n.6, p. 1419-1440, 2010.

BAUER, M.W.; AARTS, B. A construção do corpus: um princípio para a coleta de dados qualitativos. In: BAUER, M. W.; GASKELL, G (orgs.). Pesquisa qualitativa com texto, imagem e som: um guia prático. 11. ed. Petrópolis: Vozes, 2013. p. 39-63.

BERTELS, S.; LAWRENCE, T. Organizational responses to institutional complexity stemming from emerging logics: the role of individuals. Strategic Organization, v. 14, n. 4, p. 336372, 2016.

BINDER, A. For love and money: Organizations' creative responses to multiple environmental logics. Theory and Society, v. 36, n. 6, p. 547-571, 2007.

BRASIL. MINISTÉRIO DA SAÚDE. Parto, aborto e puerpério: assistência humanizada à mulher. Brasília: Ministério da Saúde, 2001.

BRENES, A. C. História da parturição no Brasil, século XIX. Cadernos de Saúde Pública, Rio de Janeiro, v. 7, n. 2, p. 135-149, 1991.

CARVALHO, R. O. Sociedade, mulher e profissão. Revista de Gestão e Secretariado - GeSec, v. 7, n. 1, p. 27-44, 2016.

CARVALHO NETO, A. M.; TANURE, B.; ANDRADE, J. Executivas: Carreira, maternidade, amores e preconceitos. RAE-eletrônica, v. 9, n. 1, 2010.

COLYVAS, J. A.; JONSSON, S. Ubiquity and legitimacy: Disentangling diffusion and institutionalization. Sociological theory, v. 29, n. 1, p. 27-53, 2011.

COSTA, M. C.; MELLO, C. M. de. Change and institutional logic: overview and proposal of analysis of different institutionalist approaches. RACE, Revista de Administração, Contabilidade e Economia, v. 16, n. 1, p. 175-202, 2017. 
DAVIS, A. Modern motherhood: Women and family in England, c. 1945-2000. Manchester: Manchester University Press, 2012.

DIAS, J. de F. 0 renascimento do parto: discurso e identidade. 2007. 248 f. Tese (Doutorado) - Programa de Pós-graduação em Linguística. Universidade de Brasília, Brasília, 2007.

DINIZ, C. S. G. Humanização da assistência ao parto no Brasil: os muitos sentidos de um movimento. Ciência Saúde Coletiva, v. 10, n. 3, p. 627-37, 2005.

DUNN, B.; JONES, C. Institutional logics and institutional pluralism: the contestation of care and science logics in medical education 1967-2005. Administrative Science Quarterly, 55, p. 114-149, 2010.

FAÚNDES, A.; CECATTI, J. A operação cesárea no Brasil: incidência, tendências, causas, consequências e propostas de ação. Caderno Saúde Pública, Rio de Janeiro, v. 7, n. 2, p.150-173, 1991.

FAVARO, C. S. Dupla jornada. Demografia Unicamp. Blog dos Estudantes. Campinas, jun. 2014. Disponível em: https://demografiaunicamp.wordpress.com/category/mudancas-nas-familias-brasileiras/. Acesso em: 28 out. 2015.

FRIEDLAND, R. The institutional logic of religious nationalism: Sex, violence and the ends of history. Politics, Religion \& Ideology, v. 12, n. 1, p. 65-88, 2011.

FRIEDLAND, R. Institution, practice, and ontology: Toward a religious sociology. Research in the Sociology of Organizations. v. 27, p. 45-83, 2009.

FRIEDLAND, R.; ALFORD, R. R. Bringing society back in: symbols, practices, and institutional contradictions. In: POWELL, W.; DIMAGGIO, P (eds.). The new institutionalism in organizational analysis. Chicago: The University of Chicago Press, 1991. p. 232-263.

FRIEDLAND, R. et al. The institutional logics of love: measuring intimate life. Theory and Society, v. 43, n. 3-4, p. 333-370, 2014.

GOODRICK, E.; REAY, T. Constellations of institutional logics: Changes in the professional work of pharmacists. Work and Occupations, v. 38, n. 3, p. 372-416, 2011.

GREENWOOD, R. et al. Institutional complexity and organizational responses. The Academy of Management Annals, v. 5, n. 1, p. 317-371, 2011.

GREENWOOD, R.; HININGS, C. R. Understanding radical organizational change: bringing together the old and the new institutionalism. Academy of Management Review, v. 21, n. 4, p. 1022-1054, 1996.

GREENWOOD, R.; HININGS, C.R.; WHETTEN, D. Rethinking institutions and organizations. Journal of Management Studies, v. 51, 2014.

GREENWOOD, R.; SUDDABY, R.; HININGS, C. R. Theorizing change: the role of professional associations in the transformation of institutionalized fields. Academy of Management Journal, v. 45, n. 1, p. 58-80, 2002.

GREVE, H. R.; ZHANG, C. M. Institutional logics and power sources: Merger and acquisition decisions. Academy of Management Journal, v. 60, n. 2, p. 671-694, 2017. 
JANCSARY, D. et al. Toward a Structural Model of Organizational-Level Institutional Pluralism and Logic Interconnectedness. Organization Science, v. 28, n. 6, p. 1150-1167, 2017.

JONES, R. H. Curso de introdução à humanização do nascimento. 2007.

KYRATSIS, Y. et al. Health systems in transition: Professional identity work in the context of shifting institutional logics. Academy of Management Journal, v. 60, n. 2, p. 610-641, 2017.

LEE, M.; LOUNSBURY, M. Filtering Institutional Logics: Community Logic Variation and Differential Responses to the Institutional Complexity of Toxic Waste. Organization Science, v. 26, n. 3, p. 847-866, 2015.

LEONE, E.T.; MAIA, A.G.; BALTAR, P.E. Mudanças na composição das famílias e impactos sobre a redução da pobreza no Brasil. Economia e Sociedade, Campinas, v. 19, n. 1, p. 59-77, 2010.

LO BIANCO, A.C. A psicologização do feto. In: FIGUEIRA, S. A (org.). Cultura da psicanálise. São Paulo: Brasiliense, 1985. p. 94-115.

LOK, J. Institutional logics as identity projects. Academy of Management Journal, v. 53, n. 6, p. 1305-1335, 2010.

LOUNSBURY, M. A Tale of Two Cities: Competing Logics and Practice Variation in the Professionalizing of Mutual Fund. Academy of Management Journal, v. 50, p. 289-307, 2007.

LOUNSBURY, M.; BOXENBAUM, E. Institutional logics in action. Research in the Sociology of Organizations, v. 39, p. 3-22, 2013.

MCPHERSON, C. M.; SAUDER, M. Logics in Action: Managing Institutional Complexity in a Drug Court. Administrative Science Quarterly, v. 58, n. 2, p. 165-196, 2013.

MICELOTTA, E.; LOUNSBURY, M.; GREENWOOD, R. Pathways of institutional change: An integrative review and research agenda. Journal of Management, p. 1-26, 2017.

MOURA, S.M.S.R. de; ARAÚJO, M. de F. A maternidade na história e a história dos cuidados maternos. Psicologia: Ciência e Profissão, v. 24, n. 1, p. 44-55, 2004.

MUTCH, A. Practice, substance and history: Reframing institutional logics. Academy of Management Review, v. 43, n. 2, 2018.

NICOLINI, D. et al. Look what's back! Institutional complexity, reversibility and the knotting of logics. British Journal of Management, v. 27, n. 2, p. 228-248, 2016.

NIGAM, A.; OCASIO, W. Event attention, environmental sensemaking, and change in institutional logics: An inductive analysis of the effects of public attention to Clinton's health care reform initiative. Organization Science, v. 21, n. 4, p. 823-841, 2010.

OCASIO, W.; LOEWENSTEIN, J.; NIGAM, A. How streams of communication reproduce and change institutional logics: the role of categories. Academy of Management Review, v. 40, n. 1, p. 28-48, 2015.

OCASIO, W.; RADOYNOVSKA, N. Strategy and commitments to institutional logics: Organizational heterogeneity in business models and governance. Strategic Organization, v. 14, n. 4, p. 287-309, 2016. 
OMS. ORGANIZAÇÃO MUNDIAL DA SAÚDE. Assistência ao parto normal: um guia prático. Brasília: Ministério da Saúde, 1996.

OREG, S. et al. An affect-based model of recipients' responses to organizational change events. Academy of Management Review, v. 43, n. 1, p. 65-86, 2018.

QUATTRONE, P. Governing social order, unfolding rationality, and Jesuit accounting practices: a procedural approach to institutional logic. Administrative Science Quarterly, v. 60, n. 3, p. 411-455, 2015.

RAMUS, T.; VACCARO, A.; BRUSONI, S. Institutional complexity in turbulent times: Formalization, collaboration, and the emergence of blended logics. Academy of Management Journal, v. 60, n. 4, p. 1253-1284, 2017.

RATTNER, D. Humanização na atenção a nascimentos e partos: breve referencial teórico. Interface - Comunicação, Saúde, Educação, v. 13, p. 595-602, 2009.

REAY, T.; HININGS, C. R. Managing the rivalry of competing institutional logics. Organization studies, v. 30, n. 6, p. 629-652, 2009.

ROSS, E. Love and toil: Motherhood in outcast London, 1870-1918. New York: Oxford University Press, 1993.

SALEM, T. A trajetória do "casal grávido": de sua constituição à revisão de seu projeto. In: FIGUEIRA, S. A (org.). Cultura da psicanálise. São Paulo: Brasiliense, 1985. p. 35-61.

SEO, M.; CREED, W. E. D. Institutional contradictions, praxis, and institutional change: a dialectical perspective. Academy of management review, v. 27, n. 2, p. 222-247, 2002.

SMETS, M.; MORRIS, T.; GREENWOOD, R. From practice to field: A multi-level model of practice-driven institutional change. Academy of Management Journal, v. 55; n. 4, p. 877-904, 2012.

SUSIN, L. R. O.; GIUGLIANI, E. R. J.; KUMMER, S. C. Influência das avós na prática do aleitamento materno. Revista de Saúde Pública, v. 39, n. 2, p. 141-147, 2005.

THORNTON, P. H.; OCASIO, W. Institutional logics and the historical contingency of power in organizations: Executive succession in the higher education publishing industry, 19581990. American Journal of Sociology, v. 105, n. 3, p. 801-843, 1999.

THORNTON, P. H.; OCASIO, W. Institutional logics. In: GREENWOOD, R. et al (eds.). The Sage handbook of organizational institutionalism. Sage, 2008. p. 99-129.

THORNTON, P. H.; OCASIO, W.; LOUNSBURY, M. The institutional logics perspective: a new approach to culture, structure, and process. Oxford University Press, 2012.

TURNER, P.K.; NORWOOD, K. Unbounded motherhood: Embodying a good working mother identity. Management Communication Quarterly, v. 27, n. 3, p. 396-424, 2013.

VALADARES, C. Pela primeira vez número de cesarianas não cresce no país. Portal da Saúde, Brasília, 10 mar. 2017. Disponível em: http://portalsaude.saude.gov.br. Acesso em: 25 set. 2017.

VELHO, M.B. et al. Vivência do parto normal ou cesáreo: revisão integrativa sobre a percepção de mulheres. Texto Contexto Enferm., Florianópolis, v. 21, n. 2, p. 458-466, 2012. 
VIEIRA, M. F. Por uma boa pesquisa (qualitativa) em administração. In: VIEIRA, M. F.; ZOUAIN, D. M (orgs.). Pesquisa qualitativa em administração. Rio de Janeiro: FGV, 2004. p. 13-28.

VILLAR, J. et al. Caesarean delivery rates and pregnancy outcomes: the 2005 WHO global survey on maternal and perinatal health in Latin America. The Lancet, v. 367, p. 18191829, 2006.

WAEGER, D. A.; WEBER, K. Institutional complexity and organizational change: An open polity perspective. Academy of Management Review. v. 44, n. 2, 2019.

WREDE, S. Introduction to Part I. In: DE VRIES, R. et al (eds.). Birth by design: Pregnancy, maternity care and midwifery in North America and Europe. Routledge, 2001. p. 3-6.

YIN, R.K. Estudo de Caso: planejamento e métodos. 2. ed. Porto Alegre: Bookman, 2001.

Data de Submissão: 28/02/2017.

Data de Aprovação: 26/07/2018. 